\title{
Prize Money Earnings of Tennis Professionals and the Impact of COVID-19 Pandemic
}

\author{
Vladimir Šimić $+1,2$ \\ ${ }^{1}$ University of Split, Faculty of Economics, Business and Tourism, Cvite Fiskovića 5, 21000 Split, Croatia \\ ${ }^{2}$ CERGE-EI Foundation Teaching Fellow, 110 Jabez Street \#1004, Newark, NJ 07105 USA
}

\begin{tabular}{l}
\hline ARTICLE INFO \\
\hline Article History \\
Received 17 February $2021 ;$ \\
Accepted 27 May 2021 \\
\hline JEL Classifications \\
J24, J33, Z21
\end{tabular}

ABSTRACT

Purpose:

The purpose of this study is to investigate the effects of COVID-19 pandemic on the earnings of tennis professionals. With the COVID-19 pandemic being an unmatched blow to the global economy resulting in one of the largest global recessions in recorded history, it might be expected that some sectors will be hit harder than others. Tennis world was particularly strongly hit, practically stopping for five long months. The corona year provides a unique occasion to revisit the issue of the earnings of top tennis professionals and make comparisons with the normal tennis years. The opportunity to collect the fresh data makes these comparisons interesting and timely.

Design/methodology/approach:

Using the most recent data we constructed the database on the prize money earnings of the TOP 100 tennis professionals. This allowed an investigation of the earnings of tennis professionals in general, but of particular interest in this paper was the impact of the COVID-19 pandemic on these earnings. The data collected for the pandemic year (2020) enabled a comparison with the normal years (2019 and 2018) revealing some interesting findings. The source of the data for investigation conducted in this study is the ATP (Association of Tennis Professionals) website.

Findings:

The empirical investigation conducted in this paper finds a strong negative impact of the COVID-19 pandemic on the tennis world and prize earnings of the top tennis professionals. The analysis also suggests that a decline in inequality among the top tennis professionals might be another consequence of the pandemic.

Keywords: COVID-19 pandemic; ATP Research limitations/implications:

players; earnings

While the empirical investigation on the impact of the COVID-19 on the tennis world conducted in this paper provides some interesting insights, it also opens a couple of avenues for future research. It might be interesting to conduct a comprehensive study of the earnings of all tennis professionals, not just those belonging to the TOP 100 group. In addition, the associated dynamics may be interesting to explore on the women's tour and make comparisons on the differences of the effects of the pandemic across the ATP and WTA tours. Data limitations might be seen as a serious obstacle for these investigations, but the analysis in this paper provides a direction as to how these obstacles might be circumvented possibly resulting in more interesting studies to come.

Originality/value:

Many studies have investigated the economic effects of the COVID-19 pandemic. With its focus on the tennis world the present study makes a contribution to the empirical literature by filling the gap on the effects of the pandemic on the sports industry. The study also opens interesting avenues for future research, especially on the impact of the pandemic on inequality.

\footnotetext{
1. Introduction

This paper investigates the effects of COVID-19 pandemic on the earnings of tennis professionals. This is an empirical study conducted to provide an additional insight into the numerous effects of COVID-19 investigated across different 
fields and activities. With the COVID-19 pandemic being an unmatched blow to the global economy resulting in one of the largest global recessions in recorded history, it might be expected that some sectors will be hit harder than others. The scary health aspects the COVID-19 brought around the world and the associated lockdowns strongly affected the tennis world practically stopping it for five long months. Even after the official tournaments resumed in August 2020, it was under very strict COVID-19 protocols and practically without audience.

The top ranked tennis players are enjoying the status of super stars earning huge money. As a theoretical background this paper takes the winner-take-all models and observes the tennis industry as a peculiar market within the business of spectacle. The corona year provides a unique opportunity to revisit the issue of the earnings of top tennis professionals and make comparisons with the normal tennis years. The chance to collect the fresh data makes these comparisons interesting and timely. This paper contributes to the empirical literature on the economic consequences of the COVID-19 pandemic by exploring the effects on the earnings of the top tennis professionals. However, it should be also noted that there emerges a large body of evidence that questions the effectiveness of lockdowns. In this context, the present study allows the comparison with the economic effects of the pandemic on other sectors.

The paper is structured as follows. Section 2 briefly outlines the effects of COVID-19 pandemic on the global economy and reviews the related literature. Empirical investigation of the TOP 100 tennis players is conducted and the main findings are reported in Section 3. Section 4 concludes.

\section{Motivation and related literature}

The year 2020 started as any other, cheerfully and optimistically. The tennis season starting early with the first tournaments beginning in parallel with the New Year celebrations gave shiny views on the tennis prospects for this year. The same positive tone might have been related to the global economy with expectations of strong growth for the global economy and prosperity all around the world ${ }^{1}$. However, soon enough the news about a strange virus occurring in China hit the headlines. Probably, with the exception of a few epidemiologists, nobody saw a big problem with it. Unfortunately, the corona virus spread really quickly around the world resulting in a pandemic that practically blocked the whole world. The COVID-19 pandemic has soon resulted in a devastating health and economic crisis making the 2020 the year of great suffering in terms of both health and people lives ${ }^{2}$ and one of the deepest recessions of the modern global economy ${ }^{3}$. The health concerns with the virus spreading around the globe with deadly consequences forced the country leaders to introduce a lockdown the world has probably never seen before. This lockdown has had devastating effects on economies around the world. The recent Global Economic Prospects (2021) published by World Bank in January reports that the global economy was hit strongly in 2020 with the estimated decline in world output of 4,3 percent, with this decline unevenly distributed around the world. Advanced economies saw the real GDP decline of 5,4 percent (with the US economy shrinking 3,6 percent, that of the euro area 7,4 percent and Japan 5,3 percent). The global trade flows were also strongly disrupted with the world trade shrinking 9,5 percent in 2020. Low income countries saw a real GDP decline of 0,9 percent. China was among the rare economies that grew in 2020, at the rate of 2,0 percent.

These numbers suggest that the lockdown caused a major disruption in the world economy, but there were economic activities (industries) that were particularly severely hit ${ }^{4}$, for example the world tourism sector. An industry closely linked to the tourism sector that might have been also strongly impacted by the COVID-19 pandemic is the sports industry $^{5}$. The present study focuses on one part of the sport industry, the tennis world and investigates the impact of the COVID-19 pandemic using the example of the ATP (Association of Tennis Professionals) tour and the earnings of the ATP TOP 100 players and the tournaments they compete in. As one might expect the money circulating in the tennis world, one of the most popular global sports, is huge and it probably comes as no surprise that the top players earn a lot. To preview the empirical investigation coming below and to give an insight into the big earnings of the top ranked tennis players let us have a look at the prize money awarded to the players that competed in the final of the first Grand Slam of the year 2020 - Australian Open ${ }^{6}$. Novak Djokovic of Serbia beat Dominic Thiem of Austria to capture the title of the first Grand Slam of the year earning A \$ 4.120.000, while Thiem received A $\$$ 2.065.000. So, for just this win in the final Djokovic earned the amount of A $\$ 2.055 .000$. A player losing in the first round of this tournament was awarded the amount of A $\$ 90.000$.

Before embarking on the empirical investigation of the earnings of the top tennis professionals and the impact of the pandemic on it in Section 3, in the remainder of this section we briefly review the related literature to help us understand the numbers that will be investigated in the empirical part of this paper.

\footnotetext{
${ }^{1}$ As reported in January 2020 the global growth was projected to rise from an estimated 2,9 percent in 2019 to 3,3 percent in 2020 (IMF World Economic Outlook, January 2020).

${ }^{2}$ As of January 92021 the World Health Organization reports 87,5 million confirmed cases in the world. More scarring is the reported number of confirmed deaths amounting to 1,9 million since the outbreak of the COVID-19 pandemic.

${ }^{3}$ European Central Bank estimates in its recent report that the COVID-19 pandemic has caused the largest short-term decline in economic activity for centuries (ECB Economic Bulletin, 2020).

${ }^{4}$ As reported by Blundell et al (2020) entire sections of the economy were ordered to shut down by the government. In the UK but also in many other countries, these sectors have included all non-food, non-pharmaceutical retail, hotels and restaurants, and arts and leisure activities (including sports). The direct and immediate economic impact has thus been concentrated among workers in these shutdown sectors.

${ }^{5}$ Evans et al. (2020) suggest that the COVID-19 prompted an almost complete shutdown of competitive sports at both the national and global level and the cancellation of competitions has placed severe pressure on wages, prize monies and livelihoods of those linked with the sport competitions.

${ }^{6}$ Note that this tournament was held under normal circumstances, with no effects of the COVID-19 pandemic on the tennis world yet.
} 
How come that tennis players earn so much money? It is not just the tennis players that earn a lot. Other popular sports also reward its top players abundantly, e.g. golf, basketball, football etc. Balliauw et al (2017) state that like other popular sports professional tennis is perceived as a lucrative profession. As reported by these authors economic explanation for the much higher income of superstars can be found in Rosen (1981), with the top tennis players, the same as the top players from other popular sports, being given the status of superstars. The underlying explanation may be briefly summarized as follows. The audience is much more interested and willing to pay to see the best players playing than the players at lower levels. This results in a bigger demand and higher earnings for the best players. On the other hand, the marginal cost of extra spectators in the stadium is negligible and this gets more pronounced with new technologies (television, internet broadcasting etc.) being available and increasing match-coverage ${ }^{7}$ Consequently, the top players (and top tournaments) can meet their high market demand easily resulting in relatively high prices and high revenues without much cost. While this explains nicely why the best players might be earning a lot, it can be also thought of as an explanation for weaker players earning less, which generates inequality in many professions, especially in tennis ${ }^{8}$. Garcia-del-Barrio and Pujol (2011) provide an alternative explanation for the high earnings in the tennis industry, which they see as a peculiar market within the business of spectacle. Tennis as a business builds upon the talent of players, whose sport performance brings forth success and sport awards. It is stressed in this study that the economic contribution of players goes far beyond their corresponding sporting achievements. This is derived from the players' media value arising from their skill and talent which is the most valuable asset and one of intangible nature. This can be also related to the concept of winner-take-all market (as proposed by Frank and Cook, 1995). This hypothesis states that the workers who are slightly better become the winner of the market, with earnings much larger than those of the losers (in magnitude much larger than the corresponding difference in productivity) ${ }^{9}$. In this context Dobson and Goddard (2001) also point to the skewed earnings distributions that may stem from scarcity of supply of outstanding talent, together with large audiences that they attract. Finally, as well recognized and documented by Garcia-del-Barrio and Pujol (2011) the media value of players (which is directly related with merchandizing, TV rights and other commercial sources of revenues) can be seen as a channel through which the high earnings in the most popular sports can be explained ${ }^{10}$.

\section{Empirical investigation}

As outlined in Section 2 the COVID-19 pandemic has caused major problems in the world in 2020. The health issues and severe consequences the pandemic has caused are unprecedented in recent history of humankind. Strong disturbances in functioning of the global economy have additionally hurt people around the world economically. Empirical investigation in this section focuses on one of the many aspects related to economic consequences of the corona virus, in the present case it being the earnings of the top 100 tennis players in the world. The analysis that follows concentrates on the ATP (Association of Tennis Professionals) tour, the tournaments the tennis players compete in and the associated earnings from the prize money in these tournaments. The investigation will focus on the TOP 100 tennis players which may be treated as a group of the most successful tennis professionals in the world. As the collection of the data is quite cumbersome and time consuming, the decision was made to focus only on this group of players.

Given the analysis in the previous section, it should not come as a surprise to learn that the tennis world has been also strongly hit by the pandemic. The lockdown from March 2020 that was introduced in most of the countries in the world practically stopped the professional tennis activities (tournaments) around the world with the tournaments being cancelled one after another. The ATP was cancelling the tournaments until July and the tournaments started only in August under very strict rules trying to contain the spreading of the virus and practically without audience. Some tournaments were postponed and some completely cancelled, but in general it can be said that the ATP tour stopped for five long months strongly hitting the tennis world and its most important protagonists, tennis professionals. It should be noted that similar conclusions could be reached and the analysis of the same type conducted on the WTA tour (the female counterpart to the male ATP tour), but given the similar principles on which these tennis tours are organized and given the difficulty related to collection of the data, this investigation is left for some future study.

In the remainder of this section we will explain as to how the data was collected and report the main findings focusing on the earnings of the ATP TOP 100 players. This investigation will then be complemented by exploring the tournaments and the prize money awarded across different levels of tournaments.

\footnotetext{
${ }^{7}$ Frick and Simmons (2007) suggest that similar to most top-tier matches in professional basketball, baseball and soccer, high-level competitions in individualistic sports, such as the top tennis tournaments attract not only thousands of spectators, but also a TV audience of millions of fans.

${ }^{8}$ Balliauw et al (2017) find that although the earnings in the tennis world are high, this particularly applying to the top ranked players, it is difficult for players with a ranking below 250 to cover their expenses.

${ }^{9}$ Ivankovic (2007) observes that by applying the tournament model similar principles can be detected on which the earnings of the top sportsmen and the top managers are determined. Citing Dye (1984) Ivankovic (2007) gives an example where the difference between the chief executive salary and the salary of a vice president is extensive, or put differently, the difference in the pay of chief executives and their immediate subordinates seems to be greater than the difference in their abilities or outputs, suggesting that the chief executives are the winners of the contest.

${ }^{10}$ Koronios et al. (2016) provide additional evidence on importance of sports sponsorship in a sport team context focusing on basketball. They report that sponsorship has gathered exceptional funding in recent decades creating business-to-business relationships with sports teams leading to creation of sources of revenues for all parties involved.
} 


\subsection{Collection of data}

The source of data for the empirical analysis conducted in this study is the ATP website (https://www.atptour.com/en/) which makes the earnings of the tennis professionals publicly available. It should be said immediately that these are the earnings from the prize money from tournaments at which tennis professionals compete and have nothing to do with the amounts the tennis players earn from lucrative contracts which they have with manufacturers of tennis equipment, clothing, commercials and so on. According to Forbes (see https://www.forbes.com/athletes/\#2113b4d655ae ) Roger Federer is the best paid athlete in the world. Forbes thus estimates that Roger Federer as one of the top tennis players earned from prize money in tournaments 6,3 million US $\$$ in 2019 , but in the same year his earnings from endorsements amounted to additional 100 million US $\$$. However, as these additional earnings are not reported and cannot be accessed publicly (with only a few exceptions including Roger Federer, Novak Djokovic and Rafael Nadal), we focus in our analysis on the earnings from prize money. In addition, the data that are reported by the ATP tour are the gross earnings and the net earnings will naturally depend on the residence of the tennis player and the tax treatment of the country in question.

This data can be accessed by opening the publicly available profile of a tennis player at the ATP tour website and then under a player's activity collecting the earnings year by year. To give an example we may mention the profile of the No. 1 in the world Novak Djokovic (see https://www.atptour.com/en/players/novakdjokovic/d643/overview). His career earnings at the end of 2020 amounted to US \$ 145.656 .177 (145 million US \$). By additionally exploring his activity, we can access his earnings per year. Thus, his earnings from prize money were 6,4 million US \$ in 2020, whilst in 2019 his prize money earnings amounted to 11,5 million US $\$$. We can investigate other years as well, but we are primarily interested in the years 2019 and 2020 to see the impact of COVID-19 on the earnings of tennis professionals. In the case of the world No. 1 this amounts to a drop of huge 44 percent. The same procedure is then applied for other ATP TOP 100 players and the database formed (constructed). The investigation of the collected database is conducted alongside different criteria (different groupings of tennis players: TOP 100, TOP50, TOP20, TOP10, those ranked 11-20, those ranked 21-30 etc.; total and average earnings of these groups across different years in US \$; percentage changes in 2020 in comparison to 2019). The results of this investigation are reported below.

\subsection{Results - prize money earnings}

In this subsection we report the results of our empirical investigation. In the graphs to follow we report the earnings of different groupings of tennis professionals.

Figure 1 - Prize money earnings (in US \$)

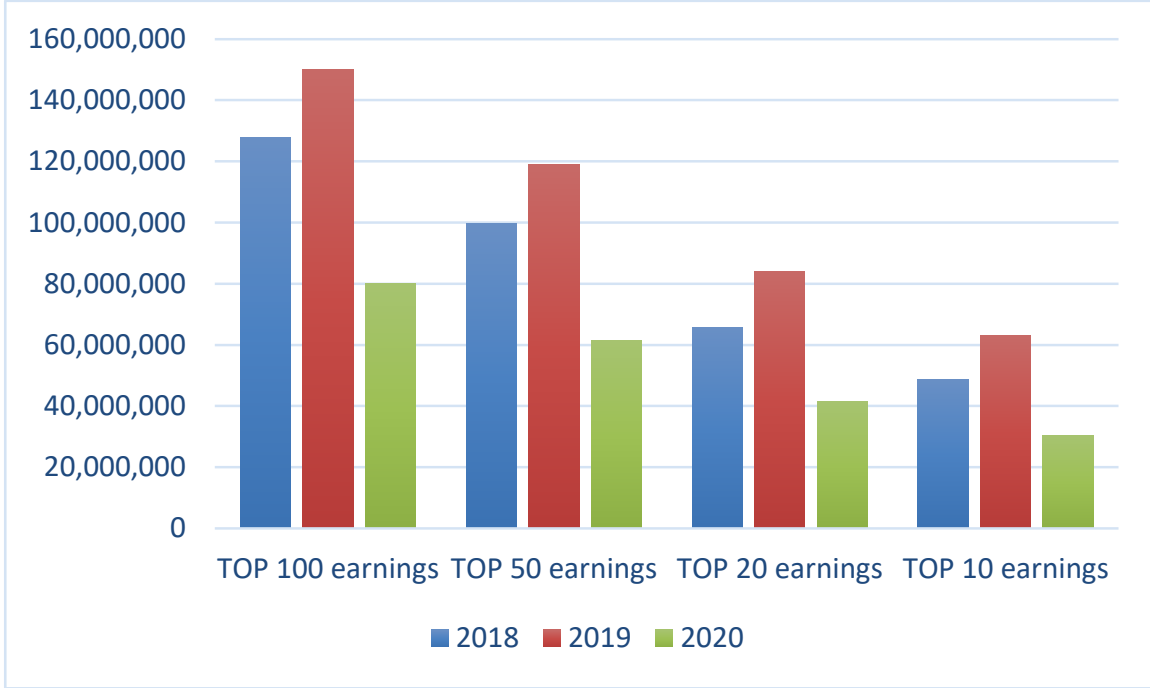

Source: ATP (https://www.atptour com/en/) and author's calculations

The data in Figure 1 offer some striking findings concerning the impact of COVID-19 on tennis world. While we can see a big increase in earnings in 2019 compared to 2018 (from 127 million US $\$$ to 150 million US $\$$ in a group consisting of the players which were the TOP 100 at the end of 2020), we can see a huge drop in 2020 in comparison to 2019 , from 150 million to 80 million US $\$$ or in percentage terms, a drop of 46 percent. It appears that the same general trends can be also observed in the TOP 50, TOP 20 and TOP 10 groups. We also report the average earnings (earnings per player) across these groups (Figure 2). 
Figure 2 - Prize money earnings per player (in US \$)

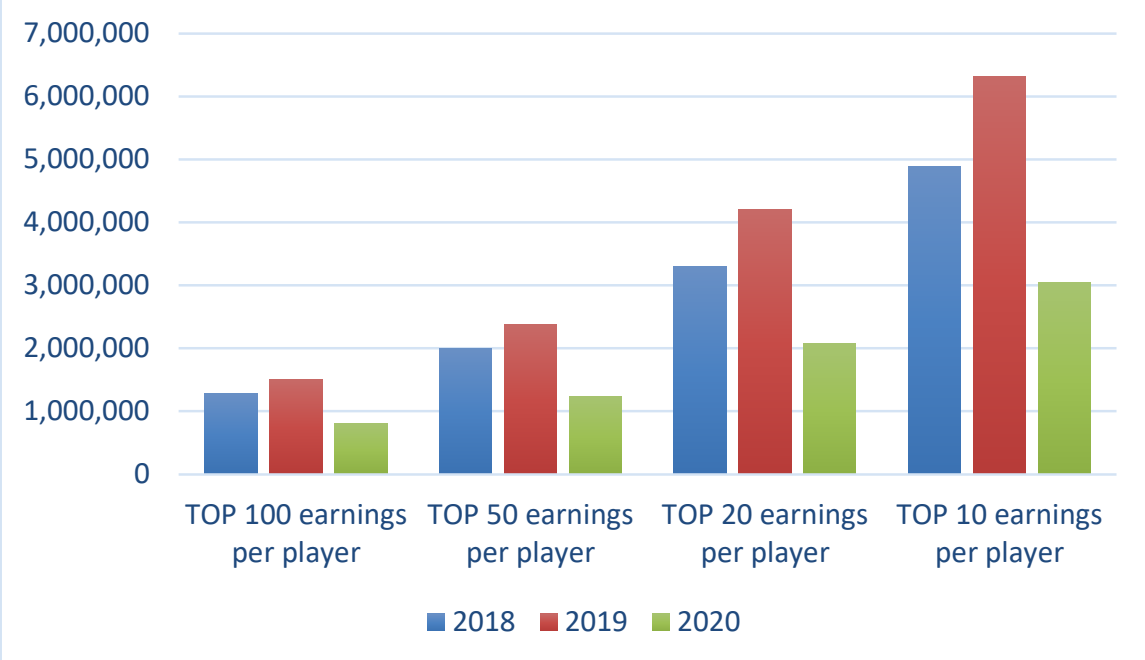

Source: ATP (https://www.atptour com/en/) and author's calculations

In Figure 2 we can see that, as expected, the same general developments can be noticed over the years as in total earnings, with an increase from 2018 to 2019, and then a huge drop in 2020. From this figure it can be also seen that earnings from the prize money per player are at a high level, this especially being the case in the TOP 10 group where the earnings per player in 2019 were 6,3 million US \$, dropping to the 3,03 million in 2020. These are, of course, high numbers but it should be kept on mind that these are the best tennis athletes in the world and the demand for their services (ability to play tennis) is quite strong. The earnings per player are lower with lower ranked groups (TOP 20, TOP 50, TOP 100) and this is nicely observed in Figure 2. We also calculated the ratio of the TOP 10 earnings in comparison with the average earnings from the groups of lower ranked players (those ranked 11-12-group named R11-20, then R21-30, R31-40, R41-50, R51-100, respectively).

Figure 3 - Ratio of TOP 10 earnings to earnings in lower ranked groups

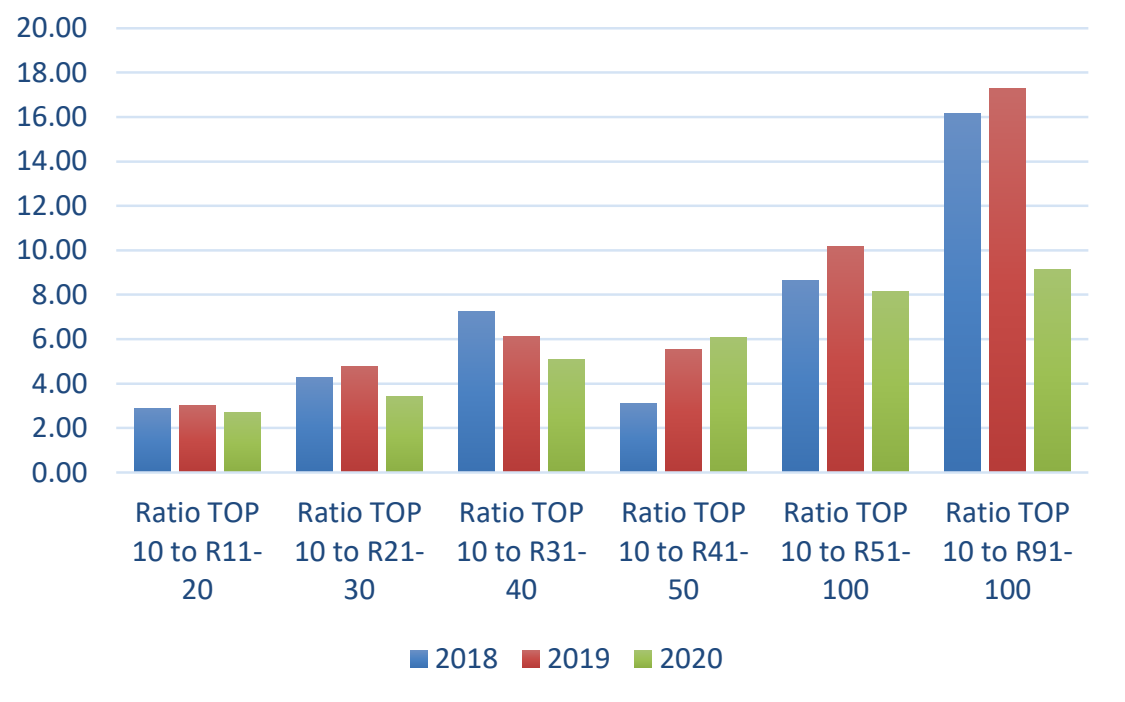

Source: ATP (https://www.atptour com/en/) and author's calculations

Earnings per player reported earlier suggested that there exist strong differences between the groups, or in other words there exists a strong inequality in earnings present in the tennis world. This can be neatly seen in Figure 3 where we report the ratio of the earnings of a player belonging to the TOP 10 group compared to the earnings of a player belonging to lower ranked groups. Thus, it appears that this ratio is above 2 if we compare the earnings from TOP 10 group and the R11-20 group (players ranked 11-20), meaning that they earn twice as much as the players from the lower ranked group. The biggest ratio is above 17 between the TOP 10 and R91-100 groups in 2019. Although not of this magnitude, similar differences can be observed in other groups as well. All this suggests that there exist large inequalities in earnings from prize money in the tennis world. However, despite the downward trend in the earnings in the pandemic year, as detected earlier, we can additionally observe from Figure 2 that this drop in earnings was not of the same magnitude in all groups that we have had an opportunity to investigate, with the pandemic year resulting in a strong decline in inequality. From the data in Figure 3 we can see that the inequalities 
across different groups increased from 2018 to 2019, but in 2020 we can notice a general decrease in the calculated ratios. This particularly applies to the ratios related to earnings of lower ranked players. Some observers might see this as a positive development and optimistically conclude this is a good consequence of the COVID-19 pandemic resulting in less inequality ${ }^{11}$. At any rate this is an interesting avenue for future research begging comprehensive study providing comparisons across different sectors/activities.

In order to shed further light on these developments the investigation of the changes in the earnings of players in different groups may be helpful. Thus, we calculated these changes in 2020 in comparison to 2019 and the associated percentage changes are reported below in Figure 4.

Figure 4-Percentage changes in earnings in different groups (2020 over 2019)

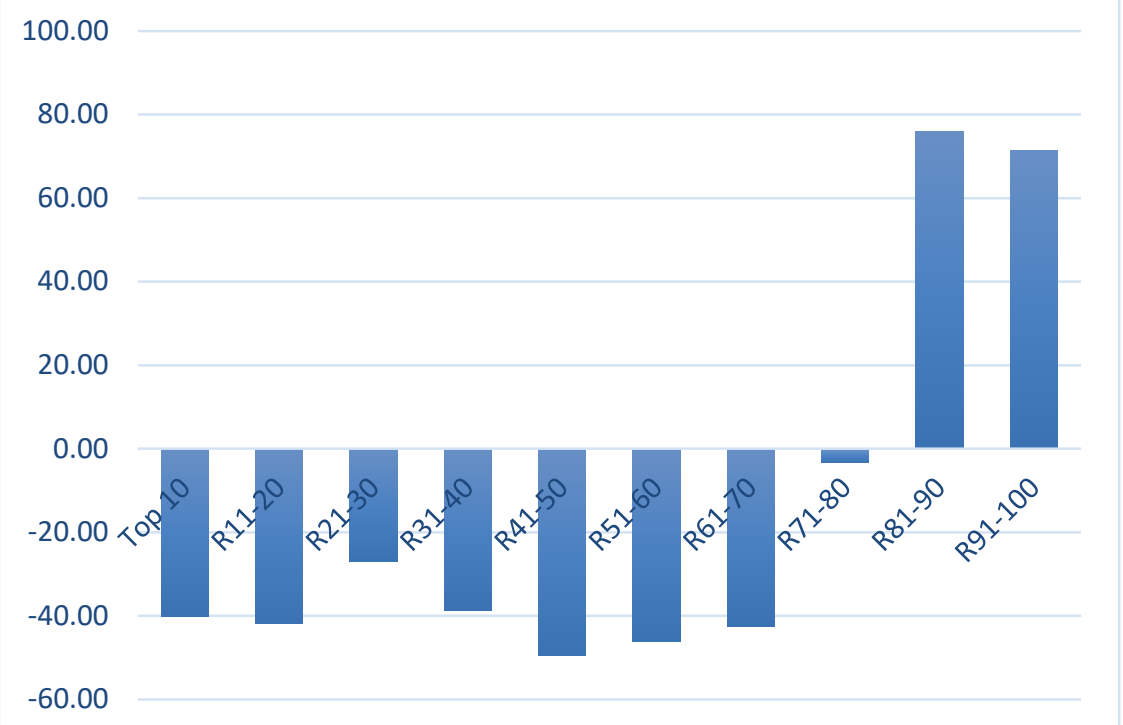

Source: ATP (https://www.atptour com/en/) and author's calculations

Before commenting on the data presented in Figure 4, let us briefly note that the change in earnings in a specific group is the average change of earnings of players belonging to that group. Namely, we calculated the percentage change for each player belonging to the TOP 100 ranking at the end of 2020, and then averaged these percentage changes across different groups. The data reported in Figure 4 is rather interesting and helps us understand the drop in inequality reported earlier. Although the drop in earnings detected in our earlier investigation might not be coming as a surprise, it is still quite a big one amounting on average to some 40 percent. However, it might be surprising to notice that with lower ranking the drop in earnings decreases, and in the two lowest ranked groups the earnings of players belonging to these groups at the end of 2020 appear to have increased. This indeed helps explain the spotted decline in inequality of earnings coming with the COVID-19 pandemic. The reasons for these differences and developments are further explored in the following subsection in which we investigate as to how the pandemic affected the ATP tour by analyzing the number of tournaments and the changes in the specific tournaments that were held both in 2019 and 2020.

\subsection{The number of tournaments and prize money on the ATP tour - 2019 vs. 2020}

As seen in previous sections COVID-19 pandemic has strongly affected most of the economic activities, with the tennis world being hit pretty strongly. As shown above the earnings of the top tennis players have declined sharply. We have already linked this decline to the lockdown imposed on most of the world economies. In addition to what was already investigated, in this subsection we analyze further the impact of COVID-19 on the number of ATP tennis tournaments and the prize money that was awarded at these tournaments. In order to investigate the mentioned effects we compare the 'normal' ATP year (2019) and the one impacted by COVID-19 (2020). Given the lockdown(s) imposed in 2020 it is expected that the number of tournaments declined strongly. This comes as a natural consequence. Possibly, it is of more interest to investigate the differences in the prize money (Total financial commitment) of the tournaments that were held. In what follows we document these differences to further show as to how large the impact of the pandemic has been.

\subsubsection{The number of ATP tournaments}

Before reporting on the effects of the pandemic on the number of tournaments, a brief explanation on the structure of the ATP tournaments is needed. The tennis men tour is run across several levels of tournaments, at the very bottom consisting of the ITF (International Tennis Federation) futures series (with prize money of US \$15.000-25.000),

\footnotetext{
11 This finding is in contrast to the now usual effect found in the recent literature with the COVID-19 pandemic exacerbating the inequalities in the society (see for example Blundell et al., 2020; Goldwin and Muggah, 2020; Stiglitz, 2020).
} 
ATP challengers (prize money up to US \$ 162.480) and at the top the ATP tournaments (ATP 250 - prize money up to US $\$ 1.416 .205$, ATP 500 - prize money up to US $\$ 3.666 .275$, ATP 1000 - prize money up to US $\$ 9.314 .875$, and the end-of-year ATP Finals - prize money US \$ 9.000.000) and Grand Slam tournaments (prize money up to US \$ 26.758.750). Table 1 below gives an idea about the importance of these tournaments with the different categories being linked to the number of ranking points and the awarded prize money. In addition two columns are added with the number of tournaments held in 2019 and 2020 across different categories.

Table 1: The structure of the men's tennis tour

\begin{tabular}{|c|c|c|c|c|}
\hline Tournament & Prize money (US $\$$ )* & $\begin{array}{c}\text { Ranking } \\
\text { points } \\
\text { (awarded to } \\
\text { the winner) }\end{array}$ & $\begin{array}{c}\text { Number of } \\
\text { tournaments in a } \\
\text { normal year }(2019)\end{array}$ & $\begin{array}{c}\text { Number of } \\
\text { tournaments in the } \\
\text { COVID-19 year } \\
(2020)\end{array}$ \\
\hline $\begin{array}{c}\text { ITF Men's World Tennis } \\
\text { Tour }\end{array}$ & & & 540 & 152 \\
\hline ITF M15 & 15.000 & 15 & 385 & 116 \\
\hline ITF M25 & 25.000 & 25 & 155 & 36 \\
\hline ATP challenger tour & & & 158 & 57 \\
\hline ATP Challenger 80 & 54.160 & 80 & 99 & 35 \\
\hline ATP Challenger 90 & 81.240 & 90 & 21 & 2 \\
\hline ATP Challenger 100 & 108.320 & 100 & 11 & 10 \\
\hline ATP Challenger 110 & 135.400 & 110 & 7 & 0 \\
\hline ATP Challenger 125 & 162.480 & 125 & 20 & 10 \\
\hline ATP tour & & & 66 & 33 \\
\hline ATP Tour 250 & 589.680 to 1.416 .205 & 250 & 39 & 18 \\
\hline ATP Tour 500 & 1.937 .740 to 3.666 .275 & 500 & 13 & 7 \\
\hline ATP Cup & & & & 1 \\
\hline ATP Tour Masters 1000 & 6.735 .690 to 9.314 .875 & 1000 & 9 & 3 \\
\hline ATP Finals & 9.000 .000 & 1500 & 1 & 1 \\
\hline Grand Slam & Up to 26.758 .750 & 2000 & 4 & 3 \\
\hline
\end{tabular}

Source: ATP (https://www.atptour.com/en/) and IMF (https://www.itftennis.com/en/)

Note: * The data refers to 2019 prize money

Table 1 explains nicely the structure of the men's tennis tournaments to provide an informed insight as to how the tour is organized and run. In what follows we will concentrate our investigation on the ATP Tour tournaments and Grand Slams. This is not to say that the other categories of tournaments (ITF Tour tournaments and ATP Challenger Tour tournaments) are of minor importance. Since it was the TOP 100 players that we focused our analysis on in the previous sub-section, and these players mostly compete in the ATP tournaments, the subsequent analysis will focus on the ATP Tour and Grand Slam tournaments. The table is in itself very informative and we will investigate the issue of prize money at different levels in detail below. At this point we find particularly striking the two last columns with the number of tournaments in 2019 and 2020. As for the ATP Tour tournaments the effect of the pandemic and the associated lockdown can be seen in the number of tournaments dropping from 66 in 2019 to 33 in 2020. Practically from the beginning of March 2020 until August 222020 no tournament was played due to the COVID-19 pandemic. Quite a lockdown we have to say. This exerted a major negative impact on the tennis world. A part of this impact was investigated in Subsection 3.2. dealing with the earnings of the top tennis players. In the remainder of this sub-section we investigate the impact of COVID-19 pandemic on the prize money awarded at the ATP tour tournaments.

\subsubsection{Prize money and the impact of COVID-19}

Given the large impact of the pandemic on economic activity (primarily the consequence of the lockdown), as established in Section 2, it is also to be expected that the amount of money circulating in the tennis world drops significantly. This was further exacerbated when the ATP tour started again in August under very strict protocols and practically without audience. This naturally decreases the revenues of the tournaments with no revenues from tickets, lower sales at tournaments, less commercials, etc. Below we document the changes in prize money awarded by tournaments (Total financial commitment per tournament, prize money awarded to the winner, and prize money awarded to the first round loser - participant fee).

In order to make this investigation easier to follow we organize our analysis across different levels of the ATP tournaments (ATP 250, ATP 500, ATP 1000, ATP Finals and Grand Slams). We compare the tournaments on the mentioned criteria from 2019 and 2020 both before the lockdown and after the tour resumed in August 2020. We first report the complete table (Table 2) and then report a couple of figures (Figures 5 and 6) to show the most important trends/changes so that the reader can easier understand the main dynamics and not get lost in too much data at one place. 
Table 2: ATP tournaments and the impact of the COVID-19 pandemic

\begin{tabular}{|c|c|c|c|c|c|c|c|c|c|}
\hline & 2019 & 2020 & & 2019 & 2020 & & 2019 & 2020 & \\
\hline $\begin{array}{l}\text { Name of } \\
\text { tournament and } \\
\text { category }\end{array}$ & $\begin{array}{l}\text { Prize } \\
\text { money (in } \\
\text { US } \$ \text { ) }\end{array}$ & $\begin{array}{l}\text { Prize } \\
\text { money (in } \\
\text { US \$) }\end{array}$ & $\begin{array}{l}\text { Chang } \\
\text { e in } \%\end{array}$ & Winner & Winner & $\begin{array}{l}\text { Chang } \\
\text { e in } \%\end{array}$ & $\begin{array}{l}\text { 1st } \\
\text { round }\end{array}$ & $\begin{array}{l}1 \mathrm{st} \\
\text { round }\end{array}$ & $\begin{array}{l}\text { Chang } \\
\mathrm{e} \text { in } \%\end{array}$ \\
\hline $\begin{array}{l}\text { Auckland ATP } \\
250\end{array}$ & 589.680 & 610.010 & 3,45 & 90.990 & 91.625 & 0,70 & 5.320 & 5.450 & 2,44 \\
\hline $\begin{array}{l}\text { Kitzbuhel } \\
\text { ATP } 250(€)\end{array}$ & 586.140 & 400.335 & $-31,70$ & 90.390 & 24.880 & $-72,47$ & 5.285 & 5.415 & 2,46 \\
\hline $\begin{array}{l}\text { Dubai ATP } \\
500\end{array}$ & 2.887 .895 & 2.950 .420 & 2,17 & 565.635 & 565.075 & $-0,10$ & 20.815 & 21.525 & 3,41 \\
\hline $\begin{array}{l}\text { Hamburg ATP } \\
500(€)\end{array}$ & 1.855 .490 & 1.203 .960 & $-35,11$ & 354.845 & 79.330 & $-77,64$ & 13.065 & 13.640 & 4,40 \\
\hline $\begin{array}{l}\text { Cincinnati } \\
\text { ATP } 1000\end{array}$ & 6.735 .690 & 4.674 .780 & $-30,60$ & $\begin{array}{c}1.114 .22 \\
5\end{array}$ & 285.000 & $-74,42$ & 22.045 & 24.560 & 11,41 \\
\hline $\begin{array}{l}\text { London ATP } \\
\text { Finals }\end{array}$ & 9.000 .000 & 5.700 .000 & $-36,67$ & $\begin{array}{c}2.656 .00 \\
0\end{array}$ & 1.564 .000 & $-41,11$ & $\begin{array}{c}215.00 \\
0\end{array}$ & $\begin{array}{c}153.00 \\
0\end{array}$ & $-28,84$ \\
\hline $\begin{array}{l}\text { Australian } \\
\text { Open (As) }\end{array}$ & $\begin{array}{c}29.687 .00 \\
\text { O }\end{array}$ & $\begin{array}{c}32.505 .00 \\
0\end{array}$ & 9,49 & $\begin{array}{c}4.100 .00 \\
0\end{array}$ & 4.120 .000 & 0,49 & 75.000 & 90.000 & 20,00 \\
\hline US Open & $\begin{array}{c}28.619 .35 \\
0\end{array}$ & $\begin{array}{c}21.656 .00 \\
0\end{array}$ & $-24,33$ & $\begin{array}{c}3.850 .00 \\
0\end{array}$ & 3.000 .000 & $-22,08$ & 58.000 & 61.000 & 5,17 \\
\hline
\end{tabular}

Source: ATP (https://www.atptour com/en/) and author's calculations

Table 2 reports the detailed data on prize money (Total financial commitment), prize money awarded to the winner of the tournament, and the prize money awarded to the player losing in the first round. All these data are reported for 2019 and 2020, as well as the percentage change in these indicators in 2020 over 2019. The tournaments held before the lockdown are colored in green. All the rest of the tournaments in the table are the tournaments held after the resumption of the tour in August 202012. The main difference that can be observed is the change in all categories depending on whether the tournament was held before the lockdown or after the resumption. Tournaments before the lockdown were running on 'the business as usual' mode seeing the increase in the total prize money, small or no increase in the prize money awarded to the winner and a relatively small increase in the prize money awarded to the first round loser (only a big increase can be observed in Australian Open). A big change can be observed in the total prize money after the tour resumed (in some tournaments amounting to a drop of considerable 30 or more percent). The winners of tournaments seem to have fared the worst with their prize money dropping as much as 74 percent as for example in the ATP Masters Cincinnati. Notwithstanding the pandemic, a good news is that those losing in the first round have generally seen their prize money increasing (with the exception of the ATP Finals in London where the participant fee saw a decline of 29 percent ${ }^{13}$ ). The general trends observed above can be seen nicely in Figures 5 and 6 below.

\footnotetext{
${ }^{12}$ Please note that not all 33 tournaments are included in the table. We decided to include representative ATP tournaments of different levels, two per category if in 2020 at least one was held before the pandemic stopped the ATP tour and one after it started again. Otherwise, only one tournament is included per category.

${ }^{13}$ Note however that only the TOP 8 tennis players qualify to compete in this tournament. Therefore, the argument offered earlier referring to lower ranked players does not really apply here.
} 
Figure 5 - Changes in ATP 250 and ATP 500 tournaments

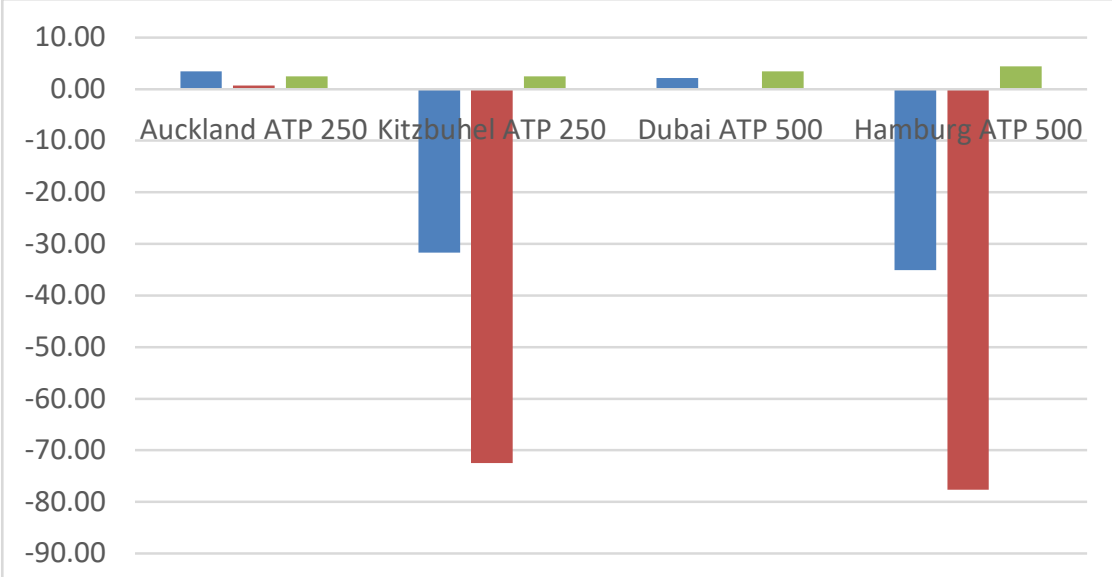

Prize money, change in \% winner, change in \% First round, change in \%

Source: ATP (https://www.atptour com/en/) and author's calculations

Figure 5 documents strikingly a big change occurring at the ATP 250 and ATP 500 level tournaments after the resumption of the ATP tour in August. The biggest decline relates to the prize money awarded to the winners of tournaments (above 70 percent), but the decline was also considerable in the total prize money (above 30 percent). Although the tournaments shrank significantly, it appears that the people in charge decided not to decrease the prize money awarded to losers in the first round, and these 'weaker' players saw small increase in the rewarded prize money ${ }^{14}$. This change probably made it easier for lower ranked and 'weaker' players to overcome the burdensome year of 2020 .

Figure 6 - Changes in ATP 1000, Grand Slams and ATP Finals

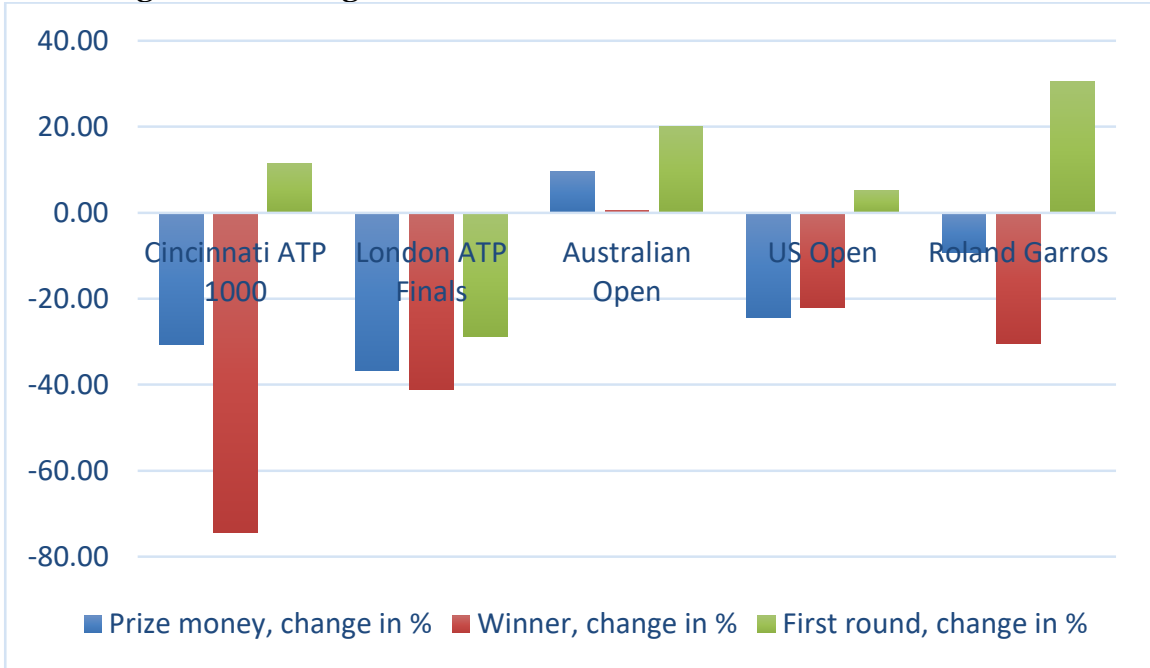

Source: ATP (https://www.atptour com/en/) and author's calculations

Figure 6 also documents these trends with the increase in the total prize money observed only in Australian Open, but this was before the pandemic started. The other world biggest tennis tournaments shrank considerably under the strong impact of the COVID-19 pandemic, with the increase in the prize money seen again only for those losing at early rounds of tournaments. These figures offer additional explanation for some of the findings reported in Subsection 3.2. In that subsection where we investigated the earnings from prize money of the ATP TOP 100 players we spotted a huge decrease in earnings of the highest ranked players (on average 40 and 41 percent for TOP 10 players and those ranked 11-20, respectively), while those ranked lower for example from 81-90 and 91-100 saw their earnings increasing in 2020 over 2019. Without intention at elaborating on this further, it is possible that although the pandemic has strongly hit the tennis world, it might have decreased some of the strong inequalities that exist between the top ranked players and those with lower rankings.

\footnotetext{
14 Given the high fixed costs for showing up in a tournament (travel arrangements and the salaries and costs for the accompanying team members coach, physio etc.) this sounds as a good decision, because with the pandemic and all of the troubles it has caused it might completely kill the incentive for lower ranked players to show up for a tournament (if their rewards are reduced) and thus possibly put in danger the very competition.
} 
While the empirical investigation on the impact of the COVID-19 on the tennis world conducted in this paper provides some interesting insights, it also opens a couple of avenues for future research. It might be interesting to conduct a comprehensive study of the earnings of all tennis professionals, not just those belonging to the TOP 100 group. In addition, the associated dynamics may be interesting to explore on the women's tour and make comparisons on the differences of the effects of the pandemic across the ATP and WTA tours. Data limitations might be seen as a serious obstacle for these investigations, but the analysis in this paper provides a direction as to how these obstacles might be circumvented possibly resulting in more interesting studies to come.

\section{Concluding remarks}

This paper explored the impact of the COVID-19 pandemic on the prize money earnings of the top tennis professionals. The pandemic has made a strong impact on the world, both in terms of health and economy. As shown in this paper the year 2020 saw one of the worst recessions in the global economy in recorded history. The lockdown(s) introduced globally have resulted in serious disturbances in the economic sphere in practically all countries in the world. The economic consequences in some sectors have been devastating. Using the most recent data we constructed the database on the prize money earnings of the TOP 100 tennis professionals. This allowed an investigation of the earnings of tennis professionals in general, but of particular interest in this paper was the impact of the COVID-19 pandemic on these earnings. The data collected for the pandemic year (2020) enabled a comparison with the normal years (2019 and 2018) revealing some interesting findings. The analysis in this paper provides an indication of a strong negative impact of the COVID-19 pandemic on the tennis world and prize earnings of the top tennis professionals. The highest ranked players have seen the biggest decline in earnings in the pandemic year, amounting to 48 percent for the TOP 50 players. The pandemic also resulted in a strong drop in prize money in tournaments, with the biggest one occurring at the ATP Finals amounting to 37 percent. Other tournaments have also considerably decreased their prize monies. However, there might be also a positive consequence of the pandemic with a decline in inequality among the top tennis professionals detected in 2020 as compared to 2019

By now many studies have investigated the economic effects of the COVID-19 pandemic. The most recent literature (see for example Allen, 2021) takes a very critical stance towards the effectiveness of lockdowns, both in terms of health and economic aspects. Through a very comprehensive review of COVID-19 literature Allen (2021) suggests that the lockdowns fail to pass a cost/benefit test. The uncertainty surrounding the impact of COVID-19 and the measures undertaken to fight it call for further research leading to a build-up of strong evidence on which to assess this particular moment in the human history. With its focus on the tennis world the present study makes a contribution to the empirical literature by filling the gap on the effects of the pandemic on the sports industry. This might lead to a better understanding of the economic effects of the pandemic and possibly allow a broader academic use which may arise through comparison to the effects of the pandemic in other sectors/activities. The study also opens interesting avenues for future research, especially on the impact of the pandemic on inequality in the sport industry.

\section{References}

Allen, D.W., 2021, "Covid Lockdown Cost/Benefits: A Critical Assessment of the Literature", April, 2021 (available at: http://www.sfu.ca/ allen/LockdownReport.pdf)

ATP Tour - Association of tennis professionals (available at: https://www.atptour.com/en/)

Balliauw, M., Verlinden, T., Van Den Spiegel, T. and Van Hecke, J., 2017, "Towards a sustainable financial model for professional tennis players", Faculty of Economics, University of Antwerp, Research Paper 2017-006

Blundell, R., Dias, M.C., Joyce, R. and Xu, X., 2020, “COVID-19 and Inequalities”, Fiscal Studies, 41, 2, pp. 291-319

Dobson, S. and Goddard, J., 2001, The Economics of Football, Cambridge University Press: Cambridge, United Kingdom

Dye, R.A., 1984, "The Trouble with Tournaments", Economic Inquiry, 22, pp. 147-149

European Central Bank, 2020, ECB Economic Bulletin (2020), Economic Bulletin, Issue 8

Evans, A.B., Blackwell, J., Dolan, P., Fahlen, J., Hoekman, R., Lenneis, V., McNarry, G., Smith, M. and Wilcock, L., 2020, "Sport in the face of the COVID-pandemic: Towards an agenda for research in the sociology of sport", European Journal for Sport and Society, pp. 1-11

Forbes (available at: https://www.forbes.com/athletes/\#2113b4d655ae)

Frank, R. and Cook, P. (1995) The winner-take-all society: How more and more Americans compete for ever fewer and bigger prizes, encouraging economic waste, income inequality, and an impoverished cultural life, Simon and Schuster, Free Press, Martin Kessler Books: New York, London and Toronto

Frick, B. and Simmons, R., 2007, "The allocation of rewards in athletic contests", Lancester University Management School Working Paper 2007/046

Garcia-del-Barrio, P. and Pujol, F., 2011, "Prize money and media value in tennis: who leads the spectacle?", (available at https://archivo.alde.es/encuentros.alde.es/anteriores/xiveea/trabajos/g/pdf/122.pdf)

Goldin, I. and Muggah, R., 2020, "COVID-19 is increasing multiple kinds of inequality. Here's what we can do about it", World Economic Forum, https://www.weforum.org/agenda/2020/10/covid-19-is-increasing-multiple-kinds-of-inequality-here-swhat-we-can-do-about-it

IMF World Economic Outlook, 2020, Tentative stabilization, sluggish recovery?, January 2020

ITF Tour - International Tennis Federation (available at: https://www.itftennis.com/en/) 
Ivankovic, M., 2007, "The tournament model: an empirical investigation of the ATP Tour", Zbornik radova Ekonomskog fakulteta u Rijeci, 25, 1, pp. 83-111

Koronios, K., Psiloutsikou, M., Kriemadis, A. and Kolovos, P., 2016, "The effect of perceived motivation of sports sponsorship: Evidence from basketball fans", International Journal of Business and Economic Sciences Applied Research, 9, 2, pp. 33-45

Rosen, S., 1981, "The economics of superstars", American Economic Review, 71 (5), pp. 845-858

Stiglitz, J., 2020, "Conquering the Great Divide", Finance and Development, September, pp. 17-19

World Bank, 2021, Global Economic Prospects, January 2021

World Health Organization (available at: https://www.who.int/)

This is an Open Access article distributed under the terms of the Creative Commons Attribution Licence

(c) (1) 